\title{
Article \\ Effects of the Multiple Injection Strategy on Combustion and Emission Characteristics of a Two-Stroke Marine Engine
}

\author{
Ju-Hwan Seol ${ }^{1}$, Van Chien Pham ${ }^{2, *(1)}$ and Won-Ju Lee ${ }^{3,4, *(D)}$ \\ 1 South Sea Fisheries Management Service, 128 Imhang-ro, Jeju-si 63280, Korea; seoljh0721@naver.com \\ 2 Graduate School, Korea Maritime and Ocean University, 727, Taejong-ro, Yeongdo-gu, Busan 49112, Korea \\ 3 Division of Marine System Engineering, Korea Maritime and Ocean University, 727, Taejong-ro, Yeongdo-gu, \\ Busan 49112, Korea \\ 4 Interdisciplinary Major of Maritime AI Convergence, Korea Maritime and Ocean University, 727, Taejong-ro, \\ Yeongdo-gu, Busan 49112, Korea \\ * Correspondence: phamvanchien.kmou@gmail.com (V.C.P.); skywonju@kmou.ac.kr (W.-J.L.); \\ Tel.: +82-51-410-4262 (W.-J.L.)
}

check for updates

Citation: Seol, J.-H.; Pham, V.C.; Lee, W.-J. Effects of the Multiple Injection Strategy on Combustion and Emission Characteristics of a Two-Stroke Marine Engine. Energies 2021, 14, 6821. https://doi.org/ 10.3390/en14206821

Academic Editor: Talal Yusaf

Received: 17 September 2021

Accepted: 14 October 2021

Published: 19 October 2021

Publisher's Note: MDPI stays neutral with regard to jurisdictional claims in published maps and institutional affiliations.

Copyright: (c) 2021 by the authors. Licensee MDPI, Basel, Switzerland. This article is an open access article distributed under the terms and conditions of the Creative Commons Attribution (CC BY) license (https:// creativecommons.org/licenses/by/ $4.0 /)$.

\begin{abstract}
This paper presents research on the effects of the multiple injection strategies on the combustion and emission characteristics of a two-stroke heavy-duty marine engine at full load. The ANSYS FLUENT simulation software was used to conduct three-dimensional simulations of the combustion process and emission formations inside the engine cylinder in both single- and double-injection modes to analyze the in-cylinder pressure, temperature, and emission characteristics. The simulation results were then compared and showed good agreement with the measured values reported in the engine's sea-trial technical reports. The simulation results showed reductions in the in-cylinder pressure and temperature peaks by $6.42 \%$ and $12.76 \%$, while NO and soot emissions were reduced up to $24.16 \%$ and $68 \%$, respectively, in the double-injection mode in comparison with the single-injection mode. However, the double-injection strategy increased the $\mathrm{CO}_{2}$ emission (7.58\%) and ISFOC $(23.55 \%)$ compared to the single-injection. These are negative effects of the doubleinjection strategy on the engine that the operators need to take into consideration. The results were in line with the literature reviews and would be good material for operators who want to reduce the engine exhaust gas emission in order to meet the stricter IMO emission regulations.
\end{abstract}

Keywords: two-stroke engine; multiple injection; combustion; emission; numerical simulation; computational fluid dynamic (CFD)

\section{Introduction}

In comparison with gasoline engines, direct injection (DI) diesel engines offer better reliability and higher thermal efficiency. Therefore, they have been being widely and commonly used not only in light-duty public transport, private vehicles but also in heavyduty marine transportation. However, because of the increasing environmental hazards of marine engine exhaust emissions, as well as the International Maritime Organization (IMO) emission regulations being more and more stringent, the exhaust gas emissions such as nitrogen oxide (NOx), soot, and carbon dioxide $\left(\mathrm{CO}_{2}\right)$ must be reduced to meet the stricter emission standards [1].

Theoretically, engine exhaust gas emission reduction approaches are divided into three categories, including (1) pre-treatment; (2) internal treatment; and (3) post-treatment [2]. In the pre-treatment approach, fuels, the main factor that affect the engine's combustion and emission characteristics, are substituted or handled prior to supply to engines. Regarding substitute fuels, various gas fuels are currently being increasingly employed in marine engines to reduce engine exhaust gas emissions. Effects of various alternative gas fuels on reducing engine exhaust gas emissions were analyzed in detail in our previous publications $[3,4]$. 
In the internal treatment approach, the combustion of the fuel inside the engine cylinder will be modified towards the goal of achieving lower exhaust gas emissions. Using innovative fuel injection systems [5,6], lean or rich combustions [7], pre-chamber type combustion, innovative combustion bowl feature [8], etc. are examples of this method. In addition, the method of adding water to the engine combustion chamber to reduce the peak temperature in the cylinder or modifying the engine working cycle (exhaust gas recirculation-EGR for example) are also other effective ways to reduce emissions. They are also being effectively used in the marine industry today.

In the post-treatment approach, it is necessary to equip exhaust gas after-treatment devices to treat the exhaust gas after it has left the engine. Using selective catalytic reduction (SCR) systems for NOx reduction is an example of this method [2]. These methods don't require modifications on fuels or existing engines, but exhaust gas after-treatment de-vices are mandatory. This results in an increase in additional costs and makes the engine room become more cramped.

Focusing on the internal treatment approach, multiple injection strategies have been proven to be effective solutions to reduce soot or even NOx and soot simultaneously in both heavy-duty DI diesel engines [9-13] and light-duty DI diesel engines [14-23]. Nehmer and Reitz [9] showed that multiple injection helps to reduce both particle matter (PM) and NOx emissions from controlled pressure rise. The effectiveness of multiple injection strategies for the simultaneous reduction of NOx and PM in DI diesel engines was also reported in [10,11,13-16,18-22]. Numerical simulations were also carried out to explore the chemical mechanism of NOx and soot reduction for multiple injection strategies by Han et al. [11]. They found that, in multiple-injection strategies, due to the subsequent injections occurred in a high-temperature environment that was produced by combustion of previous injections, the injected fuel burnt more rapidly resulting in a reduction in soot formation rates. Therefore, the net production of soot was dramatically reduced. Furthermore, soot formed in a high-temperature environment had been oxidized more effectively leading to a great reduction in engine-out soot emissions in multiple injection strategies. These previous researches have proven that multiple injection strategies have similar effects to the retarded injection strategy in the single injection method on NOx reduction applied on conventional DI diesel engines. The reduction in soot emissions is due to the fact that the soot-producing fuel-rich regions are significantly reduced when the fuel dose is divided into several times to be injected into the combustion chamber. Zhang [14] reported that the soot emission was closely related to the pilot flame (first-dose injection flame) and could be reduced by reducing this pilot flame by using only a small amount of fuel for the first injection in multiple injection strategies. Another study on multiple injection strategies was done by Tanaka et al. [16]. They also reported that it is possible to simultaneously reduce exhaust gas emissions by decreasing the influence of the pilot flame through minimizing the fuel quantity in the pilot (first-time) injection or retarding this first-time injection timing.

Meanwhile, Choi and Reitz [17] experimentally studied the effects of single and split injections on soot formation in a DI engine. They found that the split injection reduced soot emissions without penalty on NOx emissions compared with the single injection. Montgomery and Reitz [12] also reported the same finding when they evaluated the effects of EGR and multiple injections on PM and NOx emissions from a DI diesel engine. Yang and Chung also reported in [23] that, when multiple injection strategies were applied, a significant reduction in soot emissions could be achieved without penalty on NOx emissions.

Based on the literature above, it is clear that the multiple injection strategy offers an effective solution to reduce engine exhaust gas emissions. This study focuses on the combustion process and emission characteristics inside the cylinder of a two-stroke marine main engine equipped on a university's training ship.

The simulation software ANSYS Fluent with its state-of-the-art models was used to perform 3D simulations calculating the combustion process and emission formation inside 
the engine cylinder. There are two operating modes of the engine that have been simulated, including the single injection mode and the double injection mode, in order to analyze the engine in-cylinder pressure, temperature, and emission characteristics. The simulation results were then validated by comparing them with the engine's sea-trial data.

\section{Simulated Engine and CFD Analysis}

\subsection{Simulated Engine Specifications}

The research object of this study is a 2-stroke diesel marine engine. The combustion process of the engine is studied and simulated to investigate the effects of the doubleinjection strategy on the engine's in-cylinder pressure, temperature, and emission characteristics compared to those when using the conventional single-injection strategy. Two engine operating modes were simulated: (1) single-injection mode and (2) double-injection mode. In both the two modes, apart from changes in the injection strategy, other operating parameters, and thus simulation parameters were kept unchanged in order to clearly investigate the effects of the injection strategy on the engine output and emissions.

The three-dimensional (3D) model of the engine cylinder, piston, cylinder head with exhaust valve of the simulated engine is shown in Figure 1. The engine has six cylinders with only one exhaust valve on each cylinder mounted at the cylinder head center and two fuel injectors mounted symmetrically on the cylinder head. The piston surface is a U-type shape. The engine cylinder diameter and piston stroke are $420 \mathrm{~mm}$ and $1360 \mathrm{~mm}$, respectively. Specifications of the simulated engine are shown in Table 1.

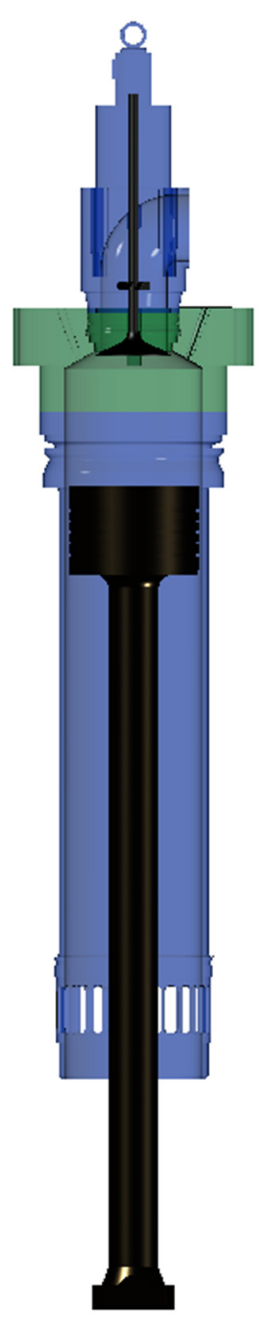

Figure 1. Structure principle schematic of the simulated engine. 
Table 1. The specifications of the simulated engine.

\begin{tabular}{ccc}
\hline Parameter & Value & Unit \\
\hline Type of Engine & \multicolumn{2}{c}{ 2-Stroke Diesel Engine } \\
Name of Engine & \multicolumn{2}{c}{ 6L42MC-ME } \\
No. of Cylinder & $620 \times 1360$ & $\mathrm{~mm}$ \\
Cylinder Bore $\times$ Stroke & 1700 & $\mathrm{~mm}$ \\
Connecting Rod Length & 13.5 & $\mathrm{~kW} @ \mathrm{rpm}$ \\
Compression Ratio & $4485 @ 160$ & $\mathrm{bar}$ \\
Rated Power @ Rated Speed & 18 & \\
IMEP & 2 & $\mathrm{~kJ} / \mathrm{kg}$ \\
No. of Fuel Injector & Diesel $\left(\mathrm{C}_{10} \mathrm{H}_{22}\right)$ & \\
Fuel & $42,343^{*}$ & \\
LCV of Diesel & &
\end{tabular}

* Provided by ANSYS Fluent database.

\subsection{CFD Analysis}

The ANSYS Fluent 2019R2 simulation software with its state-of-the-art models was employed to simulate the combustion and emission formation inside the engine cylinder. The simulation process was performed from the exhaust valve closing (EVC) to the exhaust valve opening (EVO) and included three steps: (1) pre-processing, (2) processing, and (3) post-processing. The first step included building the computational domain (Geometry), creating movable computational meshes (Meshing), and setting up the simulation parameters (Setup). The solutions were calculated in the second step. In the third step, the simulation results were analyzed and reported. After obtaining the simulation results, the simulation results and measured results were compared for the validation of the simulation models. This process was repeated until the simulation and measured results matched. Figure 2 shows the workflow of the study.

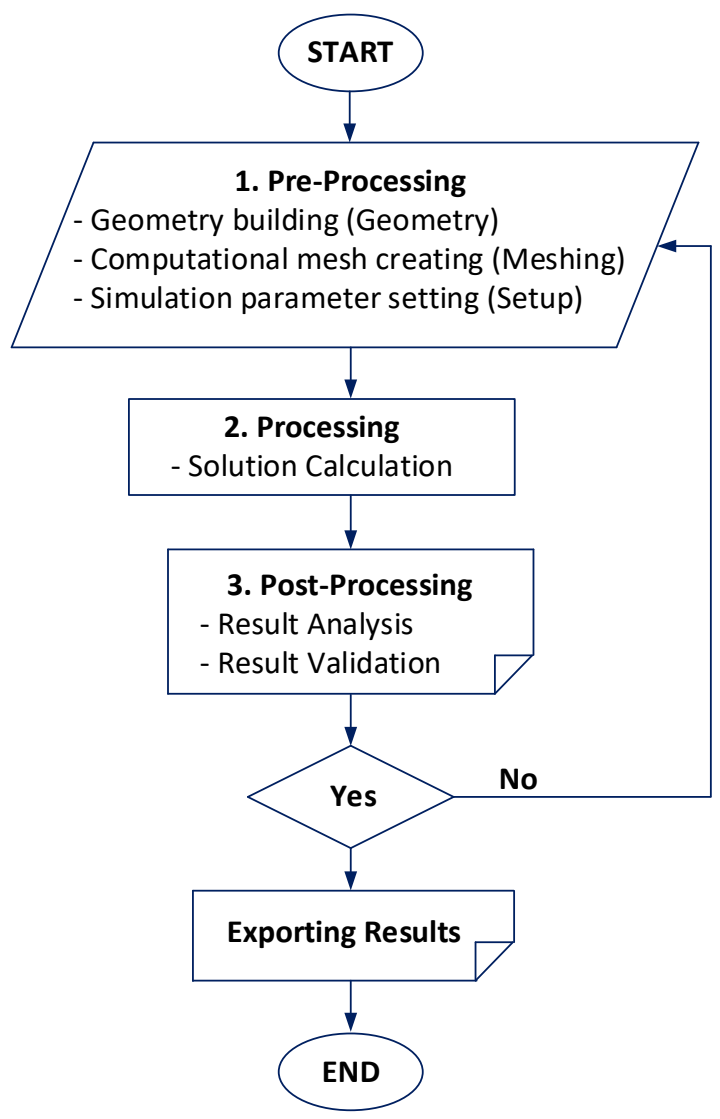

Figure 2. The workflow of the study. 
The $\mathrm{k}-\varepsilon$ turbulence model was selected to simulate the turbulence of the fluid flow inside the engine cylinder. This is the commonly widely used model in the simulation of the combustion of internal combustion engines (ICEs) [24]. To simulate the combustion process of the engine the Non-premixed Combustion model was used. This model allows simulating non-premixed combustion in which fuels and oxidizers are supplied to the combustion chamber separately [25]. The Discrete Phase Model (DPM) was used to simulate the fuel injection. This model offers a way to correct the injection velocities and initial droplet diameters due to cavitation. In order to simulate the breaking up of the phenomenon of fuel droplets, the Kelvin-Helmholtz Rayleigh-Taylor (KHRT) sub-model was used. The Auto-ignition model was used for simulating the self-ignition phenomenon that occurs in an auto-ignited diesel engine.

The Extended Zeldovich model was used to simulation the NO formation characteristic $[25,26]$. This chemical reaction mechanism consists of seven species and three reactions and is able to predict NO formation with high accuracy over a wide range of equivalence ratios. This model was presented in detail and can be found in Appendix $C$ of our previous publication [3,4]. The Moss-Brookes model [25,27] was used to simulate the soot formation due to the combustion process. To simulate the collisions and interactions between fuel droplets and walls the Stochastic Collision sub-model, which is based on the algorithm of $\mathrm{O}^{\prime}$ Rourke [25], was used. The non-premixed combustion model and Moss-Brookes soot models can be found in references [25,27]. Other CFD models can be found in references [25-27]. Table 2 shows a summary of the numerical models used in this study.

Table 2. The summary of the numerical models.

\begin{tabular}{ccc}
\hline Model & \multicolumn{2}{c}{ Description } \\
\hline Combustion & Non-premixed Combustion model [25] \\
\cline { 2 - 3 } Emission & NO & Extended Zeldovich \\
\cline { 2 - 3 } & Soot & Moss-Brookes model \\
\cline { 2 - 3 } Atomization & Spray & Kiscrete Phase Model (DPM) \\
\cline { 2 - 3 } & Breakup & Auto-ignition \\
\hline Collision & Ignition \\
\hline Turbulence & \multicolumn{2}{c}{ Stochastic Collision model } \\
\hline \multicolumn{2}{c}{ k- $\varepsilon$ turbulence model } \\
\hline
\end{tabular}

\subsection{Computational Mesh, Boundary and Initial Conditions}

The combustion chamber geometry was built by using the AutoCAD software (Autodesk, California, USA) and the computational mesh was then created by the ANSYS (Autodesk, California, USA) Meshing platform. The boundary conditions (BCs), initial conditions, and simulation parameters were declared in the setup platform. The solution was then calculated in series using an 8-core processor and took approximately $72 \mathrm{~h}$ of CPU time. Figure 3 shows half of the 3D symmetry combustion chamber geometry while Figure 4 shows half of the 3D computational mesh of the combustion chamber at the top dead center (TDC). 


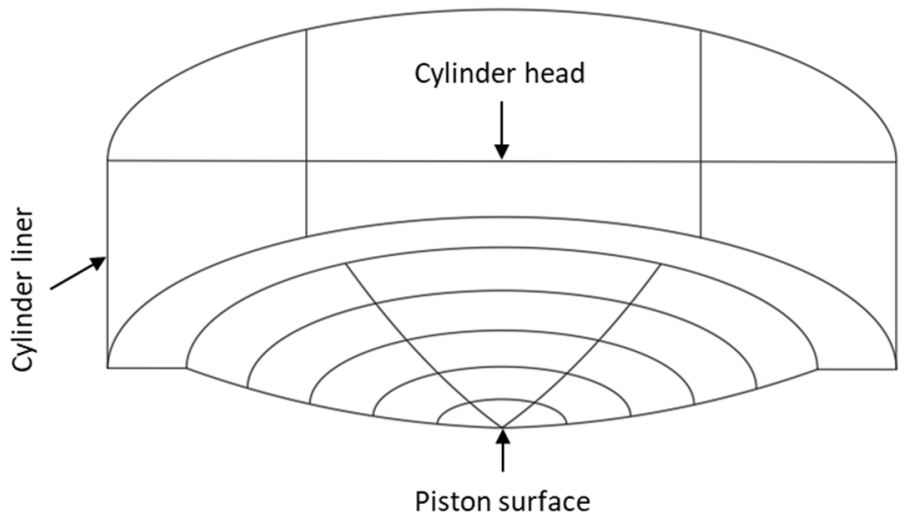

Figure 3. Half of the 3D symmetry combustion chamber geometry.

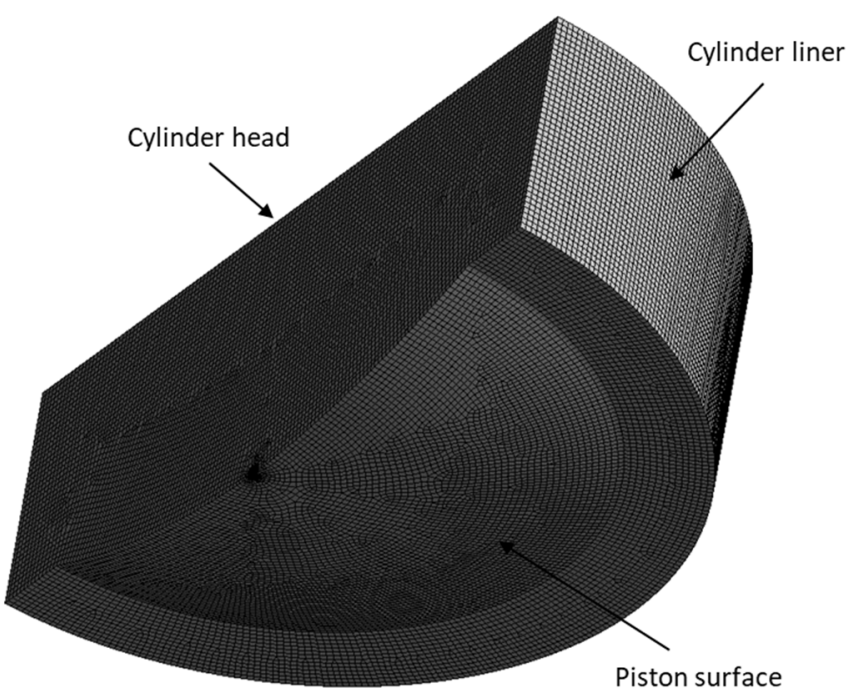

Figure 4. Half of the 3D computational mesh of the combustion chamber at the TDC.

Due to the movement of the piston, we needed to use a dynamic mesh in this study. Due to the re-meshing during calculation, the mesh quality and mesh resolution might be changed. In order to keep the mesh quality within acceptable range, we used the dynamic layering method with a collapse factor of 0.4 and a split factor of 0.4 for dynamic moving mesh modeling. The computational mesh will be re-meshed according to the movement of the piston based on the dynamic layering method. Specifically, during the piston downward movement, mesh layers will be added when the outermost layer (boundary piston surface mesh layer) height increases by more than $40 \%$ (split factor of 0.4 ) of the declared height when setting the meshing. In contrast, during the piston upward movement, mesh layers will be collapsed when the outermost layer height decreases by more than $40 \%$ (collapse factor of 0.4 ) of the declared height. This means that the number of mesh layers and thus the number of elements will be increased or decreased according to the moving down or up of the piston. In this way, the mesh quality and resolution will be kept almost unchanged during calculation.

Due to the specificity of the dynamic layering method, we have used hexahedral elements for computational mesh. This type of elements is also the most perfect for computational mesh due to its very high orthogonal quality. We had also performed a lot of simulations with different mesh resolutions (coarse, medium, and fine) until meshindependence of the calculation results was achieved. Finally, we obtained the final mesh with parameters as shown in Table 3. 
Table 3. Mesh Statistics and Quality.

\begin{tabular}{cc}
\hline \multicolumn{2}{c}{ Mesh Statistics and Quality } \\
\hline Type of elements & Hexahedral \\
\hline No. of nodes at the TDC & 459,058 \\
\hline No. of elements at the TDC & 508,650 \\
\hline Aspect ratio & 17.05 \\
\hline Maximum Skewness ratio & 0.76 \\
\hline Minimum Orthogonal quality & 0.45 \\
\hline
\end{tabular}

The BCs at the cylinder head, piston surface and cylinder liner were defined as impermeable wall BCs. The cylinder geometry was planed symmetric, so the cyclic BCs were assigned to the cutting surfaces of the computational domain. The simulation was started from the EVC of $30 \mathrm{CAD}$ after the bottom dead center (ABDC) (EVC $=30 \mathrm{CAD}$ $\mathrm{ABDC})$ to the $\mathrm{EVO}$ of $30 \mathrm{CAD}$ before the bottom dead center (BBDC) $(\mathrm{EVO}=30 \mathrm{CAD}$ BBDC). The schematic of the engine working cycle is shown in Figure 5 while Figure 6 shows the start of injection (SOI) and injection duration in both the single and double injection modes.

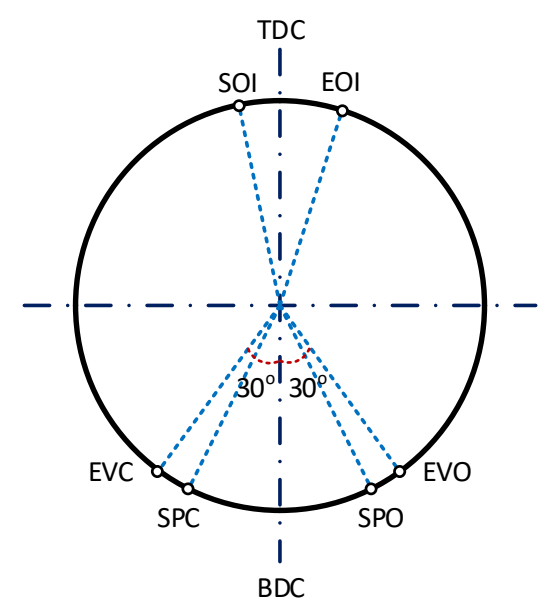

Figure 5. The schematic of the engine working cycle (TDC: Top dead center; BDC: Bottom dead center; EVO: Exhaust valve opens; EVC: Exhaust valve closes; SPO: Scavenging-air port opens; SPC: Scavenging-air port closes; SOI: Start of injection; EOI: End of injection).

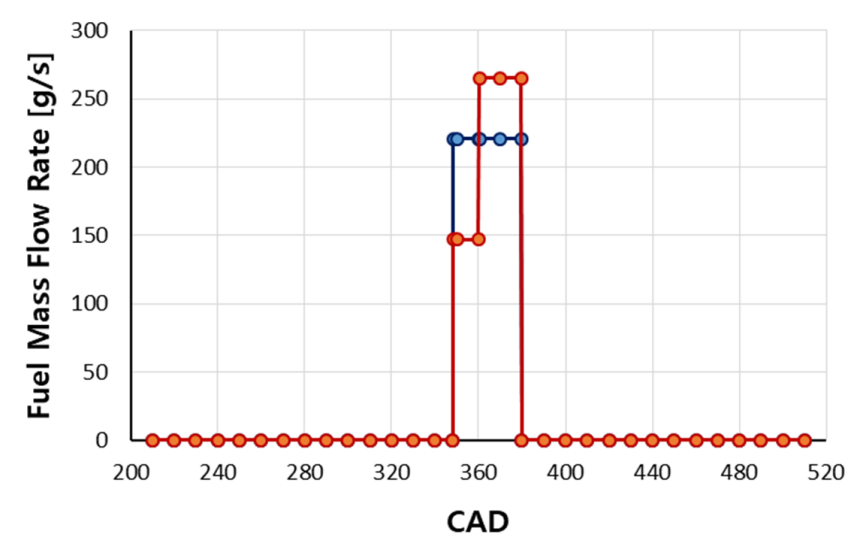

$\multimap-$ Single $\rightarrow$ Double

Figure 6. Injection properties in the operating modes. 
The BCs and initial conditions were chosen from the sea-trial report of the actual engine provided by the operating officer. Table 4 shows the BCs and initial conditions for the numerical simulation cases.

Table 4. Boundary conditions and initial conditions for the numerically simulation cases.

\begin{tabular}{cc}
\hline Boundary Conditions & Boundary Type/Specific Condition \\
\hline Cylinder head & Wall/Temp. $/ 297^{\circ} \mathrm{C}$ \\
\hline Piston & Mesh movement $/$ Temp. $/ 297^{\circ} \mathrm{C} \mathrm{K}$ \\
\hline Liner & Wall $/$ Temp. $/ 197^{\circ} \mathrm{C}$ \\
\hline Segment cut & Cyclic \\
\hline Initial conditions & Value \\
\hline Scavenging air Press. & 2.0 bar \\
\hline Scavenging air Temp. & $28{ }^{\circ} \mathrm{C}$ \\
\hline EVC & 30 CAD ABDC \\
\hline EVO & 30 CAD BBDC \\
\hline SOI & 12 CAD BTDC \\
\hline Injection duration & 32 CAD \\
\hline
\end{tabular}

\subsection{Simulation Cases and Fuel Properties}

In this study, the combustion process of the engine running in two fuel injection modes at full load was simulated, including single injection and double injection. In single injection mode, fuel was injected directly into the engine's combustion chamber in just one injection. Meanwhile, the fuel was divided into two injections to inject into the engine's combustion chamber in double injection mode. All other simulation conditions were kept unchanged. The properties of the diesel fuel are shown in Table 5.

Table 5. The diesel fuel properties $[25,28,29]$.

\begin{tabular}{ccc}
\hline Fuel & Diesel & Unit \\
\hline Density & 730 & $\mathrm{~kg} / \mathrm{m}^{3} @ 25{ }^{\circ} \mathrm{C}, 1$ at \\
Chemical name/formula & Diesel/ $\mathrm{C}_{10} \mathrm{H}_{22}$ & $\mathrm{~kJ} / \mathrm{kg}$ \\
Lower calorific value & 42,000 & $\mathrm{~kg} / \mathrm{kmol}$ \\
Molecular weight & 142.284 & ${ }^{\circ} \mathrm{C}$ \\
Boiling point & 174 & ${ }^{\circ} \mathrm{C}$ \\
Auto-Ignition temperature & 223 & $\mathrm{~J} / \mathrm{kg} \cdot \mathrm{K} @ 25^{\circ} \mathrm{C}$ \\
Specific heat capacity $(\mathrm{Cp})$ & 2090 &
\end{tabular}

The simulation results were then validated against the engine's sea-trial data provided by the engine manufacturer. The simulation results showed a good agreement with the measured results written in the engine's sea-trial technical reports and were presented in detail in Section 3-Simulation results.

\section{Simulation Results}

To clearly investigate the effects of the injection strategy on the combustion and emission characteristics of the engine, all of the BCs and engine's working conditions were kept unchanged, excepting the difference in the fuel injection strategy. In this section, the in-cylinder pressure, temperature and emissions characteristics of the engine will be presented and analyzed.

\subsection{In-Cylinder Pressure}

The simulated in-cylinder pressure diagrams in both injection modes are shown in Figure $7 \mathrm{a}$ while Figure $7 \mathrm{~b}$ shows the comparison between simulated and experimental peak 
pressure inside the engine cylinder obtained from the sea-trial. As can be seen in Figure 7, the peak pressures in both single and double injections are similar to those in comparison with the experimental results. The deviation between simulated and experimental results in the single injection mode was only $4.85 \%$, while it was $8.3 \%$ in the double injection mode. These deviations are acceptable in CFD analysis. Comparing the two simulation cases, the results showed that the in-cylinder peak pressure in the double injection mode was $6.42 \%$ lower than that compared with the single injection mode (Figure 7a).

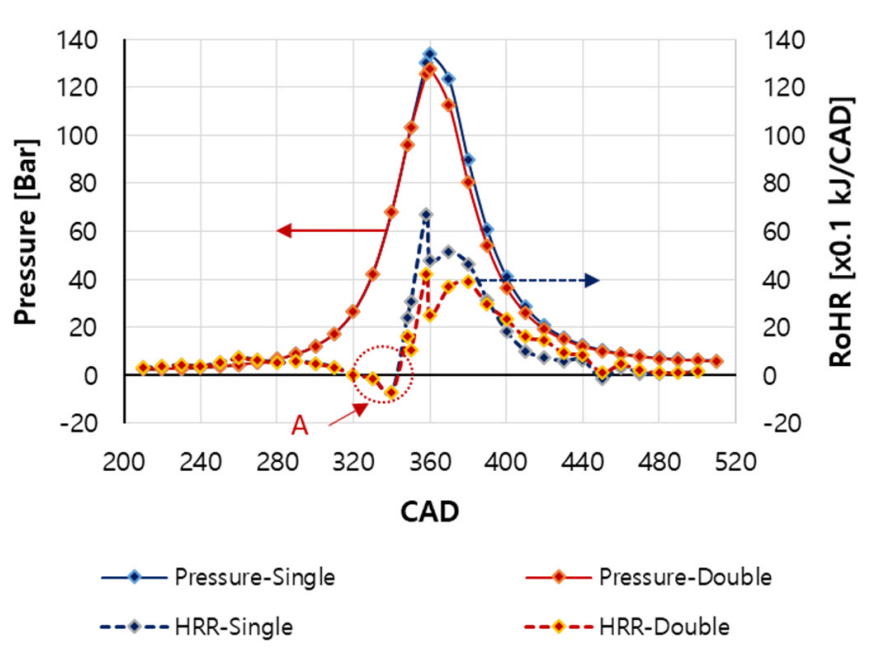

A: Cooling effects due to fuel injections

(a)

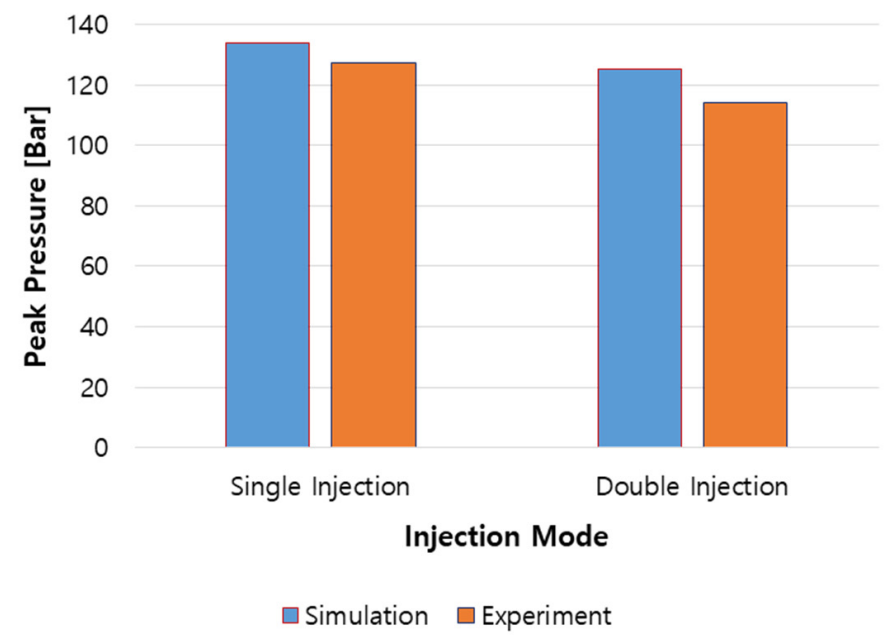

(b)

Figure 7. Simulated cylinder pressure diagrams (a) and comparison between simulated and experimental peak pressure (b).

As shown in Figure 6, in the double injection mode, since only $25 \%$ of the total fuel was injected into the engine cylinder before the TDC and $75 \%$ of the total fuel was injected from the TDC, the rate of heat release (RoHR) in the engine cylinder before the TDC in the double injection mode was lower than that in the single-injection mode. From the TDC, even though the fuel injected into the engine cylinder in the double injection mode was higher than that in the single-injection mode, but the fuel was injected after the TDC when the piston was in the downward movement. These resulted in a reduction in the in-cylinder peak pressure in the double injection mode compared with the single-injection mode, as shown in Figure 7a. The reductions in the in-cylinder peak pressure when using multiple injection strategy were also reported by Nehmer and Reitz in [9], and Qiu et al. in [22].

\subsection{In-Cylinder Temperature}

The in-cylinder temperature diagrams with RoHR traces in both simulation cases are shown in Figure 8. The simulation result showed that the in-cylinder peak temperature in the double-injection mode was lower than that in comparison with the single-injection mode. However, the mean in-cylinder temperature in the double-injection mode was higher than that compared with the single-injection mode during the expansion process. This resulted in a higher exhaust gas temperature in the double-injection mode compared to the single-injection mode.

As the same as in-cylinder peak pressure, the decrease in the in-cylinder peak temperature in double-injection compared with single-injection is the result of less fuel being injected before the TDC, resulting in lower RoHR inside the engine cylinder. On the other hand, more fuel was injected into the engine cylinder after the TDC in the double-injection mode resulting in a higher RoHR inside the engine cylinder and thus higher in-cylinder temperature during the expansion process as can be seen in Figure 8. 

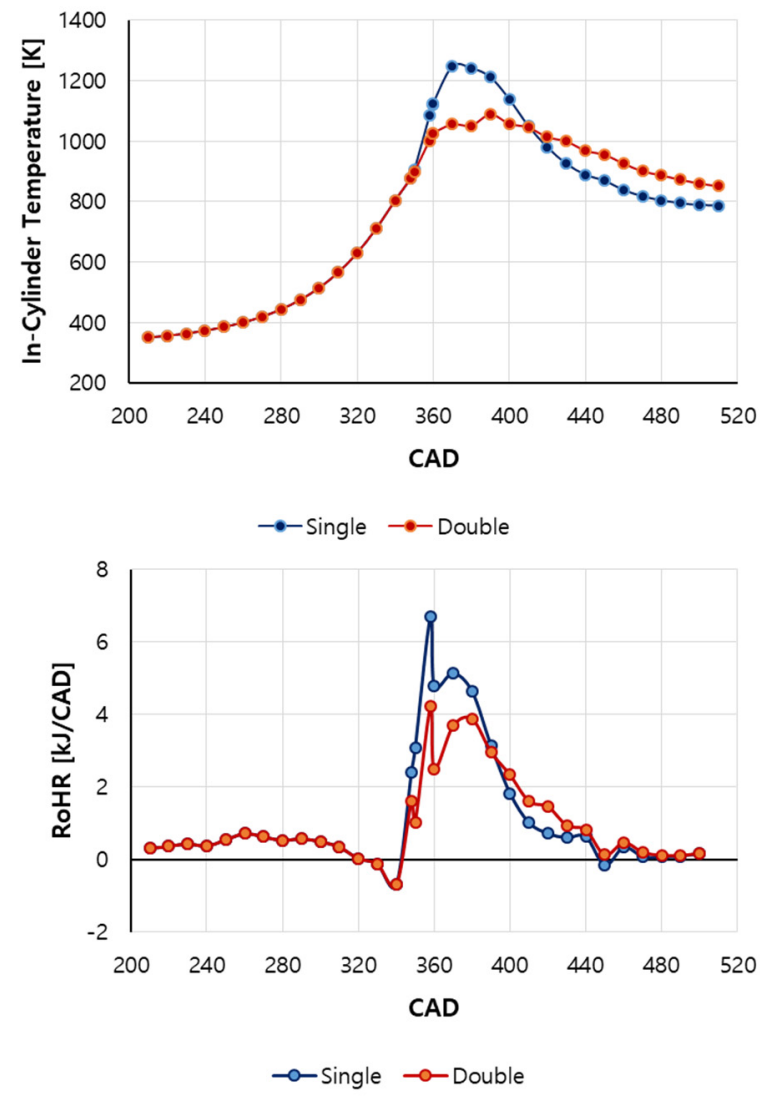

Figure 8. Simulated cylinder temperature diagrams with RoHR traces in both simulation cases.

\subsection{NO Emission}

The NO emissions generated in both injection modes are shown in Figure 9a, while Figure $9 \mathrm{~b}$ shows the comparison between simulated and experimental $\mathrm{NO}$ emission of the engine obtained from the sea-trial. As can be seen in Figure 9a, the NO emission generated in the double injection mode was $24.16 \%$ lower than that compared with the single injection mode. Figure $9 \mathrm{~b}$ shows a very good agreement between Simulated and experimental NO emission in both injection modes. The deviation between simulated and experimental results in the single injection mode was only $3.6 \%$, while it also was only $3.62 \%$ in the double injection mode.

According to the extended Zelodovich NO formation mechanism, the NO formation is greatly influenced by the in-cylinder temperature peak and oxygen $\left(\mathrm{O}_{2}\right)$ concentration within the engine cylinder. NO formation occurs in regions in the cylinder where the local temperature is above $1800 \mathrm{~K}$ and the formation rate increase significantly with the increase of the local in-cylinder temperature [30-32]. The simulation results showed a reduction of $12.76 \%$ in the in-cylinder temperature peak in the double-injection mode compared to the single-injection mode (Figure 8). This resulted in a reduction of $24.16 \%$ in NO emission in the double-injection mode in comparison with the single-injection mode as shown in Figure 9a. Reduction effects on NOx emission as well as soot (PM) have been reported by Fang et al. in their publication on Fuel, 2008 [18] and other researchers in [9-11,13-16,19-22]. 


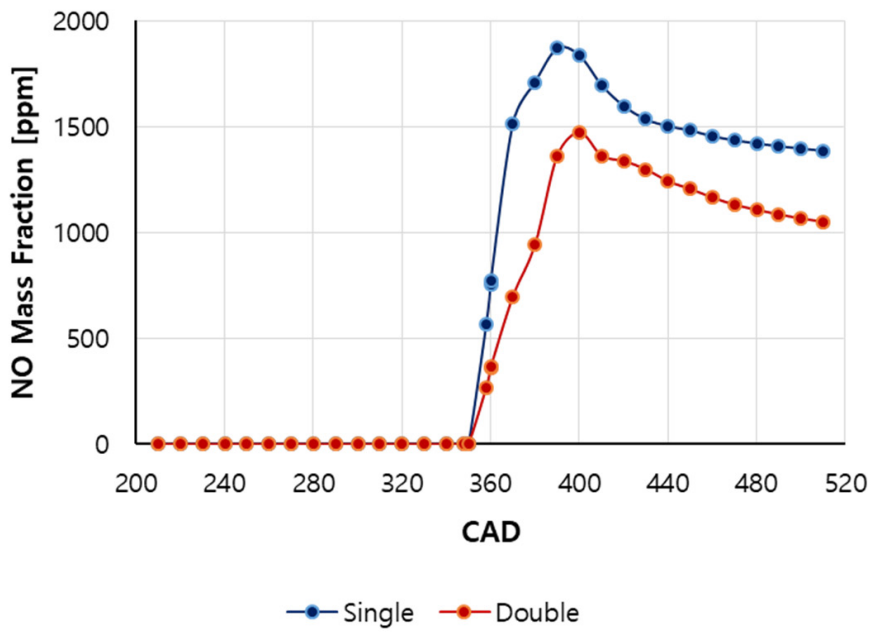

(a)

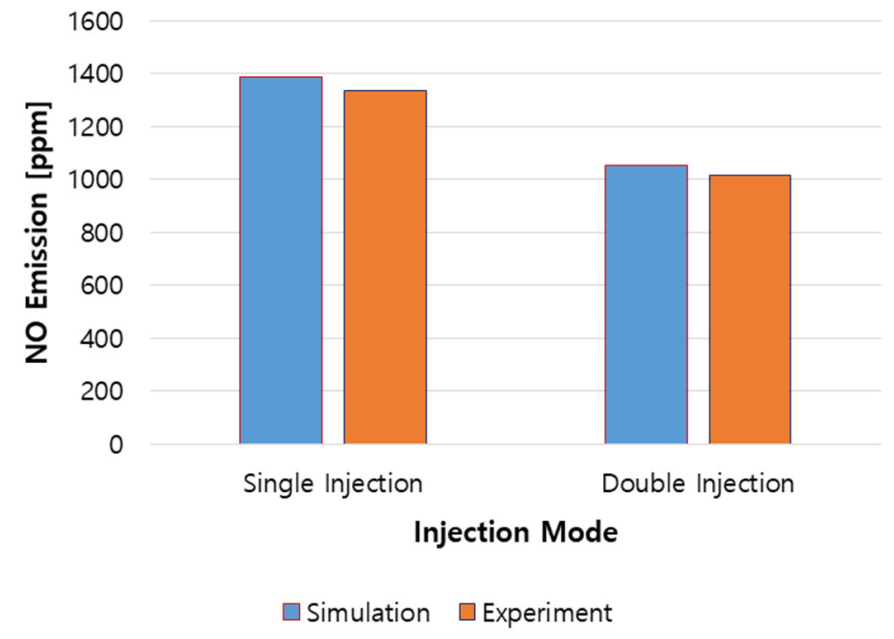

(b)

Figure 9. The mean NO mass fraction diagrams (a) and comparison between simulated and experimental NO emission (b).

\subsection{Soot Formation}

Soot is the main component of particulate matter (PM) emission [33-36]. Under high temperature and equivalence ratios (fuel-rich conditions), which are typically found in diesel diffusion combustions, hydrocarbon fuels have a strong tendency to form carbonaceous particles, i.e., soot. Soot particles are formed very early in the diffusion combustion process because of the dissociation of fuels under high temperature and high equivalence ratio conditions. Usually, under normal engine running conditions of diesel engines, most of the soot that formed in the early combustion stage will be depleted due to oxidation in the late stages of the combustion. This typically takes place in oxygen-rich regions of the combustion chamber in the late stage of the engine cycle (expansion process). Therefore, in diesel engines, the soot formation, and completeness of the soot oxidation process determines the particle emission characteristics of the engine [34]. The parameters that play the most important role during the soot formation inside the engine cylinder are the local equivalence fuel/air ratio (C/H-ratio and C/O-ratio), in-cylinder temperature, pressure, and residence time [34].

Under ideal reaction conditions, the products of hydrocarbon fuel combustions are only $\mathrm{CO}_{2}$ and $\mathrm{H}_{2} \mathrm{O}$. The amount of oxygen required for a complete chemical reaction (the stoichiometric oxygen requirement- $\mathrm{O}_{2}$, stoichiometric) can be calculated from the following reaction equation [25]:

$$
\mathrm{C}_{n} \mathrm{H}_{m} \mathrm{O}_{k}+\left(n+\frac{m}{4}-\frac{k}{2}\right) \mathrm{O}_{2} \rightarrow n \mathrm{CO}_{2}+\frac{m}{2} \mathrm{H}_{2} \mathrm{O}
$$

In the above equation $k, m$, and $n$ represent the number of oxygen, hydrogen and carbon atoms of the considered fuel, respectively.

The actual amount of oxygen available for combustion is expressed by the air access ratio $\lambda$ or by its inversion, the equivalence (fuel-air) ratio $\phi$ :

$$
\phi=\frac{1}{\lambda}=\frac{O_{2, \text { stoichiometric }}}{O_{2, \text { actual }}}
$$

The soot formations in both injection modes are shown in Figure 10. The simulation results showed that the maximum soot emission generated in the double-injection mode was reduced up to more than $68 \%$. In addition, the soot mass fraction plot in the doubleinjection mode showed two peaks as can be seen in Figure 10. This is the result of the double-injection strategy in which the fuel dose was divided into two injections to be injected into the engine cylinder. 


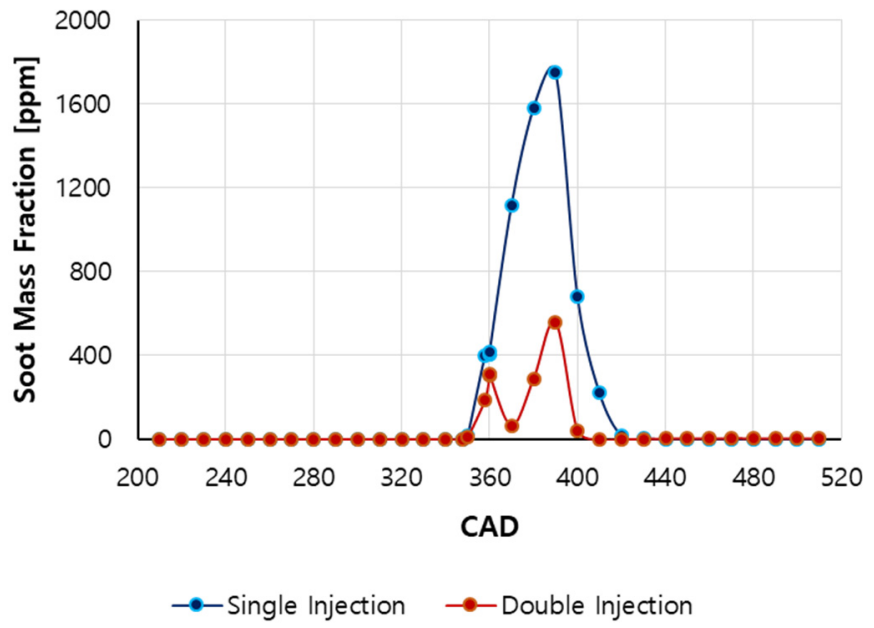

Figure 10. The mean soot mass fraction diagrams.

Reduction in soot formation is explained as the reduction effect in the fuel/air equivalence ratio $\phi$. By dividing the fuel dose into two injections, the mass fraction of fuel in each injection was decreased resulting in a reduction in the fuel/air equivalence ratio, the factor that mainly and strongly affects the soot formation in ICEs as widely known. Figure 10 also showed that, in the double-injection mode, the amount of soot produced inside the engine cylinder was not only reduced but they were also completely oxidized more quickly in comparison with the single-injection mode. This is because the oxidation of soot in the cylinders has been promoted by higher cylinder temperatures during the engine expansion process in the double-injection. Once again, reduction effects on soot as well as NOx emission when using double-injection strategy is in line with the report by Fang et al. in their publication on Fuel, 2008 [18] and other researchers in [9-17,19-23].

In addition, Tree et al. mentioned in [37] that fuel pyrolysis plays an important role in soot formation in compression-ignition engines (CIEs). Pyrolysis is a process that changes the molecular structure of organic compounds, such as fuels, under high-temperature conditions without significant oxidation although $\mathrm{O}_{2}$ species may be present. All fuels will undergo pyrolysis and produce basically the same species: polyacetylenes, polycyclic aromatic hydrocarbons (PAH), unsaturated hydrocarbons, and especially acetylene. Pyrolysis reactions are usually endothermic owing to the fact that their rates are strongly temperature-dependent [38]. Fuel pyrolysis leads to the production of some species which are precursors or building blocks for soot. Fuel pyrolysis to form soot precursor increase with temperature. Therefore, soot increases as the temperature increases. The same tendency was also reported in $[39,40]$. In this study, as presented in Figure 8, the in-cylinder peak temperature was reduced in the double-injection strategy. As a result, this resulted in a decrease in soot formation inside the engine cylinder, as shown in Figure 10.

\subsection{Carbon Dioxide $\left(\mathrm{CO}_{2}\right)$ Emission}

The $\mathrm{CO}_{2}$ mass fraction in both injection modes is shown in Figure 11a, while Figure 11b shows the comparison between simulated and experimental $\mathrm{CO}_{2}$ emission of the engine obtained from the sea-trial. The simulation results pointed that the $\mathrm{CO}_{2}$ emission in the case of double-injection was $7.58 \%$ higher than that of single-injection (Figure 11a). In comparison with the experimental results, the deviation between the simulated and experimental $\mathrm{CO}_{2}$ mass fraction was $7.36 \%$ (Figure $11 \mathrm{~b}$ ) and acceptable in CFD analysis. 


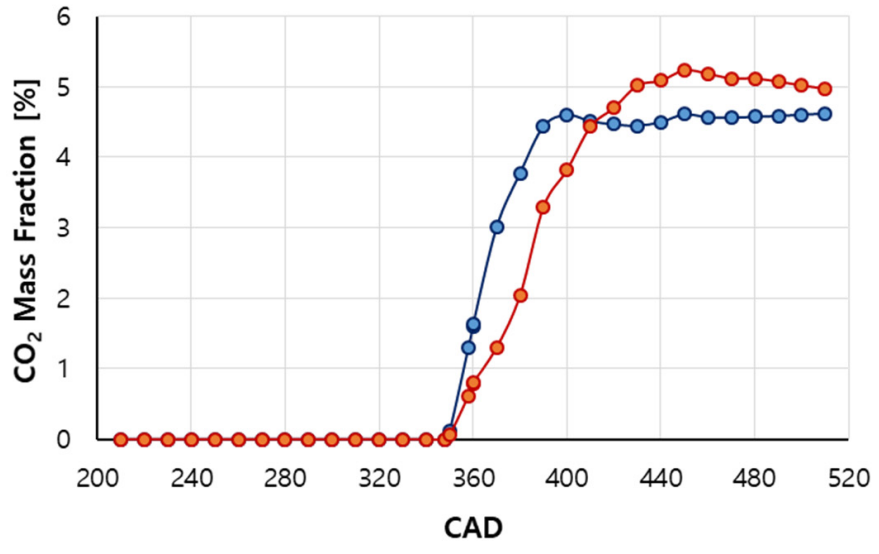

$\rightarrow-$ Single Injection $\rightarrow-$ Double Injection

(a)

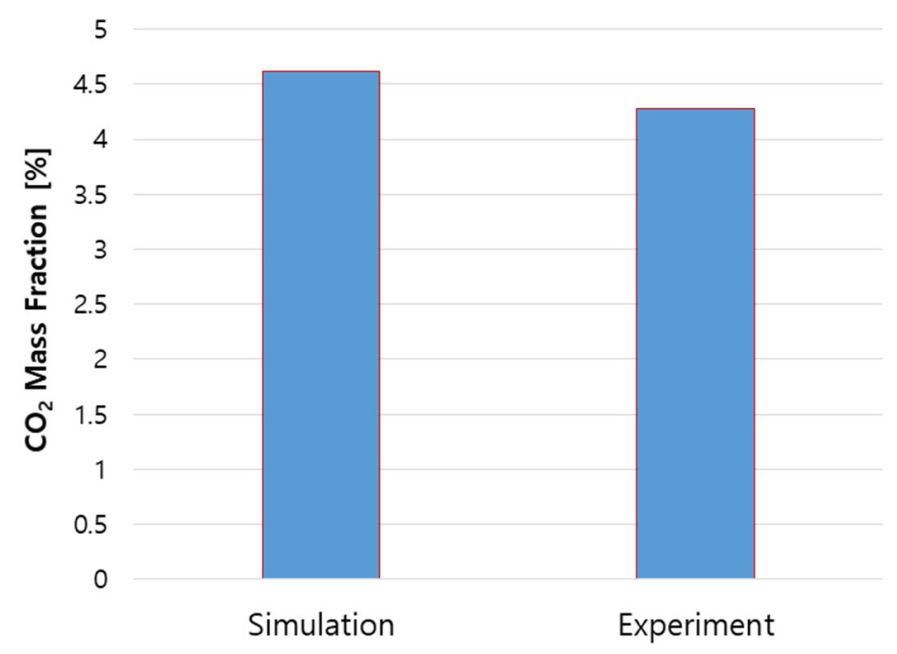

(b)

Figure 11. The mean $\mathrm{CO}_{2}$ emission diagrams (a) and comparison between simulated and experimental $\mathrm{CO}_{2}$ emission (b).

Regarding the reasons for the increasing $\mathrm{CO}_{2}$ emission in the double-injection mode, as has been known, carbon dioxide is a product of the complete combustion of hydrocarbon fuels. Firstly, hydrocarbon fuels will be oxidized to $\mathrm{CO}$ during the combustion process, and then it is oxidized to form $\mathrm{CO}_{2}$ sequentially if the in-cylinder temperature is high enough and there is still enough $\mathrm{O}_{2}$ in the cylinder. Therefore, $\mathrm{CO}_{2}$ formation strongly depends on the in-cylinder temperature and the concentration of oxygen in the engine cylinder. As can be seen in Figure 8, even though the in-cylinder peak temperature in the double-injection mode was lower than that in the single-injection mode, but the in-cylinder temperature during expansion stroke was higher because most of the fuel ( $75 \%$ of mass) was injected and burned after the TDC, in the late combustion phase of the double-injection mode. The higher temperature inside the engine cylinder during the late stage of the combustion in the case of double-injection mode promoted $\mathrm{CO}$ oxidation to produce $\mathrm{CO}_{2}$ resulting in an increase in $\mathrm{CO}_{2}$ emission in the double-injection mode in comparison with the single-injection mode, as shown in Figure 11a.

\subsection{Specific Fuel Oil Consumption}

Figure 12 shows the indicated specific fuel oil consumption (ISFOC) in both injection modes. The simulation results showed an increase in the ISFOC of the engine when operated in the double-injection mode. Specifically, the ISFOC was increased $23.55 \%$ when operating the engine in the double-injection mode compared to that in the single-injection mode. The increase in the ISFOC can be explained by a decrease in the peak pressure in the cylinder leading to a decrease in engine power when operated in the double-injection mode. This result points that using the double-injection strategy to reduce $\mathrm{NO}$ and soot emission not only results in an increase in $\mathrm{CO}_{2}$ emission but also an increase in the SFOC of the engine. These are negative effects of the double-injection strategy on the engine that the operators need to take into consideration when operating the engine. 


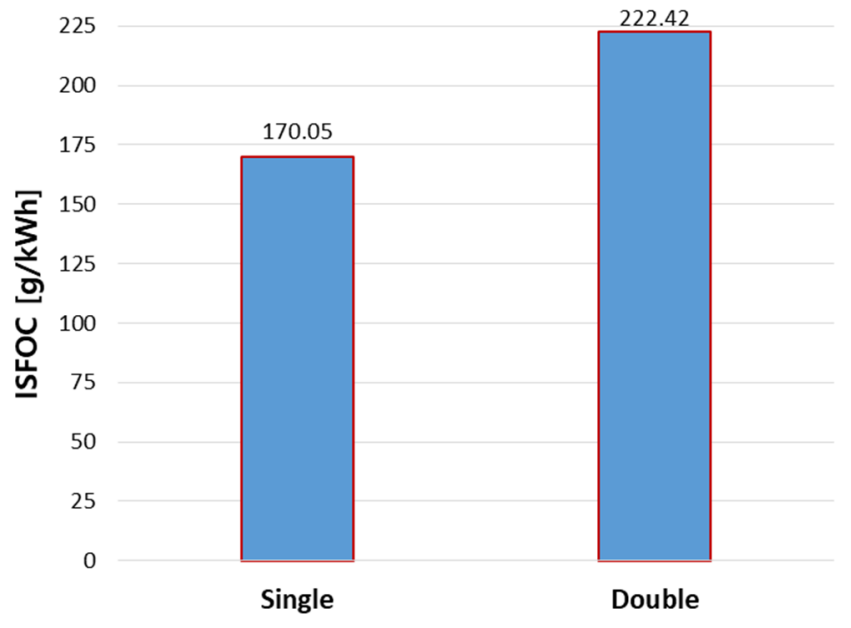

Figure 12. The ISFOC of the engine in both injection modes.

\section{Conclusions}

This paper numerically investigated the effects of the double-injection strategy on the combustion and emission characteristics of a two-stroke diesel marine engine. The simulation results were then compared and showed good agreement with the measured results obtained from the engine's sea-trials.

The main outcomes of the study are as follows:

- The in-cylinder peak pressure in the double-injection mode was $6.42 \%$ lower compared with the single injection mode.

- The in-cylinder peak temperature in the double-injection mode was lower in comparison with the single-injection mode resulting in a significant reduction in NO emission $(24.16 \%)$.

- The maximum soot emission generated in the double-injection mode was reduced by more than $68 \%$ in comparison with the single-injection mode.

- However, the double-injection strategy increased the $\mathrm{CO}_{2}$ emission $(7.58 \%)$ and ISFOC $(23.55 \%)$ compared to the single-injection. These are negative effects of the doubleinjection strategy on the engine that the operators need to take into consideration when operating the engine.

The results were in line with the existing literature and provides good material for operators who want to reduce engine exhaust gas emissions in order to meet the stricter IMO emission regulations.

Author Contributions: Conceptualization, V.C.P. and W.-J.L.; Methodology, V.C.P. and W.-J.L.; Software, V.C.P.; Validation, J.-H.S. and W.-J.L.; Formal analysis, J.-H.S.; Data curation, J.-H.S. and W.-J.L.; Writing-original draft preparation, V.C.P.; Writing-review and editing, V.C.P. and J.-H.S.; Project administration, W.-J.L.; Funding acquisition, W.-J.L. All authors have read and agreed to the published version of the manuscript.

Funding: This research was supported by the Ministry of Education of Republic of Korea and the National Research Foundation of Korea (NRF-2019R1G1A1005342) and by the Ministry of Science and ICT of Republic of Korea and National IT Industry Promotion Agency (S1226-21-1001).

Institutional Review Board Statement: Not applicable.

Informed Consent Statement: Not applicable.

Data Availability Statement: Not applicable.

Conflicts of Interest: The authors declare no conflict of interest. 


\section{References}

1. Thomson, H.; Corbett, J.J.; Winebrake, J.J. Natural gas as a marine fuel. Energy Policy. 2015, 87, 153-167. [CrossRef]

2. Woodyard, D. Pounders Marine Diesel Engines and Gas Turbines, 9th ed.; Elsevier: Burlington, MA, USA, 2009.

3. Pham, V.C.; Choi, J.H.; Rho, B.S.; Kim, J.S.; Park, K.N.; Park, S.K.; Le, V.V.; Lee, W.J. A numerical study on the combustion process and emission characteristics of a natural gas-diesel dual-fuel marine engine at full load. Energies 2021, 14, 1342. [CrossRef]

4. Pham, V.C.; Rho, B.-S.; Kim, J.-S.; Lee, W.-J.; Choi, J.-H. Effects of various fuels on combustion and emission characteristics of a four-stroke dual-fuel marine engine. J. Mar. Sci. Eng. 2021, 9, 1072. [CrossRef]

5. Martin, G.C.; Mueller, C.J.; Milam, D.M.; Radovanovic, M.S.; Gehrke, C.R. Early direct-injection, low-temperature combustion of diesel fuel in an optical engine utilizing a 15-hole, dual-row, narrow-included-angle nozzle. SAE Int. J. Engines 2008, 1, $1057-1082$. [CrossRef]

6. Polonowski, C.J.; Mueller, C.J.; Gehrke, C.R.; Bazyn, T.; Martin, C.M.; Lillo, M. An experimental investigation of low-soot and soot-free combustion strategies in a heavy-duty, single-cylinder, direct-injection, optical diesel engine. SAE Int. J. Fuels Lubr. 2012, 5, 51-77. [CrossRef]

7. Dunn-Rankin, D. Lean Combustion Technology and Control; Elsevier Ltd.: Amsterdam, The Netherlands; Academic Press: Boston, MA, USA, 2011.

8. Belgiorno, G.; Boscolo, A.; Dileo, G.; Numidi, F.; Pesce, F.C.; Vassallo, A.; Ianniello, R.; Beatrice, C.; Blasio, G.D. Experimental study of additive-manufacturing-enabled innovative diesel combustion bowl features for achieving ultra-low emissions and high efficiency. SAE Int. J. Adv. Curr. Pract. Mobil.-V130-99EJ 2021, 3, 672-684. [CrossRef]

9. Nehmer, D.A.; Reitz, R.D. Measurement of the effect of injection rate and split injections on diesel engine soot and NOx emissions. SAE Pap. 1994, 940668.

10. Tow, T.C.; Pierpont, D.A.; Reitz, R.D. Reducing particulate and NOx emissions by using multiple injections in a heady duty DI diesel engine. SAE Pap. 1994, 940897.

11. Han, Z.; Uludogan, A.; Hampson, G.J.; Reitz, R.D. Mechanism of soot and NOx emission reduction using multiple injection in a diesel engine. SAE Pap. 1996, 960633.

12. Montgomery, D.T.; Reitz, R.D. Six-mode cycle evaluation of the effect of EGR and multiple injections on particulate and $\mathrm{NO}_{x}$ emissions from a DI diesel engine. SAE Tech. Pap. 1996, 960316.

13. Pierpont, D.A.; Montgomery, D.T.; Reitz, R.D. Reducing particulate and NOx using multiple injections and EGR in a D.I. diesel. J. Fuels Lubr. 1995, 104, 171-183.

14. Zhang, L. A study of pilot injection in a DI diesel engine. SAE Pap. 1999, 1, 3493.

15. Chen, S.K. Simultaneous reduction of NOx and particulate emissions by using multiple injections in a small diesel engine. SAE Pap. 2000, 1, 3084.

16. Tanaka, T.; Ando, A.; Ishizaka, K. Study on pilot injection of DI diesel engine using common rail injection system. JSAE Rev. 2002, 23, 297-302. [CrossRef]

17. Choi, C.Y.; Reitz, R.D. An experimental study on the effects of oxygenated fuel blends and multiple injection strategies on DI diesel engine emissions. Fuel 1999, 78, 1303-1317. [CrossRef]

18. Fang, T.; Coverdill, R.E.; Lee, C.F.; White, R.A. Effects of injection angles on combustion processes using multiple injection strategies in an HSDI diesel engine. Fuel 2008, 87, 3232-3239. [CrossRef]

19. Chacko, N.; Rajkumar, S.; Thanragaja, J. Experimental and modeling analysis of multiple-injection strategies with B20 operation in a CRDI engine. Fuel 2021, 293, 120433. [CrossRef]

20. Plamondon, E.; Seers, P. Parametric study of pilot-main injection strategies on the performance of a light-duty diesel engine fueled with diesel or a WCO biodiesel-diesel blend. Fuel 2019, 236, 1273-1281. [CrossRef]

21. Jorques Moreno, C.; Stenlaas, O.; Tunestal, P. Influence of small pilot on main injection in a heavy-duty diesel engine. SAE Tech. Pap. 2017, 1, 708. [CrossRef]

22. Qiu, L.; Cheng, X.; Liu, B.; Dong, S.; Bao, S.Z. Partially premixed combustion based on different injection strategies in a light-duty diesel engine. Energy 2016, 96, 155-165. [CrossRef]

23. Yang, S.Y.; Chung, S.H. An experimental study on the effects of high-pressure and multiple injection strategies on DI diesel engine emissions. In SAE Technical Paper Series; SAE International: Warrendale, PA, USA, 2013.

24. Durbin, P.A. Near-wall turbulence closure modeling without "damping functions". Theor. Comput. Fluid Dyn. $1991,3,1-13$.

25. ANSYS Fluent Theory Guide; ANSYS, Inc.: Canonburg, PA, USA, 2013; Available online: http:/ / www.ansys.com (accessed on 7 July 2021).

26. Rao, V.; Honnery, D. A comparison of two NOx prediction schemes for use in diesel engine thermodynamic modelling. Fuel 2013, 107, 662-670. [CrossRef]

27. Brookes, S.; Moss, J. Predictions of soot and thermal radiation properties in confined turbulent jet diffusion flames. Combust. Flame. 1999, 116, 486-503. [CrossRef]

28. PubChem Compound. n-heptane-Compound Summary. National Center for Biotechnology Information. 8600 Rockville Pike, Bethesda MD, 20894 USA. 16 September 2004. Available online: https:/ / pubchem.ncbi.nlm.nih.gov/compound/8900 (accessed on 7 September 2020).

29. Friend, D.G.; Ely, J.F. and Ingham, H. Thermophysical properties of methane. J. Phys. Chem. Ref. Data 1989, 18, 583. [CrossRef]

30. Heywood, J.B. Internal Combustion Engine Fundamentals; McGraw-Hill Education: New York, NY, USA, 1998. 
31. Wei, L.; Geng, P. A review on natural gas/diesel dual fuel combustion, emissions and performance. Fuel Process. Technol. 2016, 142, 264-278. [CrossRef]

32. Kuo, K.K. Principles of Combustion, 2nd ed.; John Wiley and Sons: New York, NY, USA, 2005.

33. Maricq, M.M.; Chase, R.E.; Xu, N.; Laing, P.M. The effects of the catalytic converter and fuel sulfur level on motor vehicle particulate matter emissions: Light duty diesel vehicles. Environ. Sci. Technol. 2002, 36, 283-289. [CrossRef]

34. Burnett, R.T.; Cakmak, S.; Brook, J.R.; Krewski, D. The role of particulate size and chemistry in the association between summertime ambient air pollution and hospitalization for cardiorespiratory diseases. Environ. Health Perspect. 1997, 105, 614-620. [CrossRef]

35. Kittelson, D.B.; Watts, W.F.; Johnson, J.P. On-road and laboratory evaluation of combustion aerosols -part 1: Summary of diesel engine results. J. Aerosol Sci. 2006, 37, 913-930. [CrossRef]

36. Rounce, P.; Tsolakis, A.; York, S.A.P.E. Speciation of particulate matter and hydrocarbon emissions from biodiesel combustion and its reduction by after-treatment. Fuel 2012, 96, 90-99. [CrossRef]

37. Tree, D.R.; Svensson, K.I. Soot processes in compression ignition engines. Prog. Energy Combust. Sci. 2007, 33, 272-309. [CrossRef]

38. Smith, O.I. Fundamentals of soot formation in flames with application to diesel engine particulate emissions. Prog. Energy Combust. Sci. 1981, 7, 275-291. [CrossRef]

39. Gowthaman, S.; Sathiyagnanam, A.P. Effects of charge temperature and fuel injection pressure on HCCI engine. Alex. Eng. J. 2016, 55, 119-125. [CrossRef]

40. Pan, W.; Yao, C.; Han, G.; Wei, H.; Wang, Q. The impact of intake air temperature on performance and exhaust emissions of a diesel methanol dual fuel engine. Fuel 2015, 162, 101-110. [CrossRef] 